\title{
A REORGANIZAÇÃO DO TRABALHO EM RIO GRANDE-RS A PARTIR DA IMPLEMENTAÇÃO DA INDÚSTRIA NAVAL ${ }^{1}$
}

\author{
Rogério Faé2 \\ Guilherme Dornelas Camara ${ }^{3}$ \\ Diego D'Avila da Rosa ${ }^{4}$
}

http://dx.doi.org/10.1590/1413-2311.213.84252

\section{RESUMO}

O estudo buscou entender as consequências da implementação da indústria naval na organização do trabalho na cidade de Rio Grande/RS. Para tal, propõe-se o conceito de organização do trabalho como o resultado de uma relação de forças antagônicas que, dinamizada por mecanismos de produção, organizam formas contraditórias de produzir a vida. O trabalho é entendido como fundante do ser e da práxis social, de modo que organizálo extrapola a mera distribuição das atividades nos locais onde ocorre a produção econômica. A partir de estudo exploratório, na cidade de Rio Grande, constatou-se que a implantação e posterior crise do polo naval provocaram alterações nas diversas dimensões da vida dos trabalhadores e da comunidade local. O investimento na indústria naval incitou a migração de trabalhadores que vislumbraram no polo naval de Rio Grande possibilidades de obter trabalho ou melhorar a renda. Agora, Rio Grande enfrenta o declínio da indústria naval que ameaça inclusive a manutenção dos estaleiros na cidade. Ao final, se considera que a forma de

\footnotetext{
${ }^{1}$ Recebido em 25/06/2018, aprovado em 08/10/2018

2 Universidade Federal do Rio Grande do Sul - Escola de Administração; Porto Alegre - RS (Brasil) rogerio.fae@ufrgs.br

3 Universidade Federal do Rio Grande do Sul - Escola de Administração; Porto Alegre - RS (Brasil) guilherme.dornelas@ufrgs.br

${ }^{4}$ Universidade Federal de Rio Grande; Rio Grande - RS (Brasil) - diego.rosa@,furg.br
} 
organização do trabalho reorganiza a vida social, tanto em nível individual quanto na comunidade como um todo e que há um predomínio do favorecimento do processo de acumulação do capital.

KEYWORDS: Organization of labour. Rio Grande. Shipyard.

\title{
LA REORGANIZACIÓN DEL TRABAJO EN RIO GRANDE-RS DESDE LA IMPLEMENTACIÓN DE LA INDUSTRIA NAVAL
}

\begin{abstract}
RESUMEN
El estudio buscó comprender las consecuencias de la implementación de la industria naval en la organización del trabajo en la ciudad de Rio Grande. Así, se propone el concepto de organización del trabajo como el resultado de una relación de fuerzas antagónicas que, dinamizada por mecanismos de producción, organizan formas contradictorias de producir la vida. El trabajo es entendido como fundante del ser y de la praxis social, de modo que organizarlo extrapola la mera distribución de las actividades en los locales donde se da la producción económica. A partir de un estudio exploratorio, en la ciudad de Rio Grande, se constató que la implantación y posterior crisis del polo naval provocaron alteraciones en diversas dimensiones de la vida de los trabajadores y de la comunidad. La inversión en la industria naval ha traído incentivos a la migración de trabajadores que vislumbraron en el polo naval posibilidades de obtener trabajo o mejorar sus ingresos. Ahora, Río Grande enfrenta el declive de la industria naval que amenaza incluso el mantenimiento de los astilleros en la ciudad. Al final, se considera que la forma de organización del trabajo reorganiza la vida social, tanto a nivel individual y en la comunidad como un todo y que hay un predominio del favorecimiento del proceso de acumulación del capital.
\end{abstract}

PALABRAS CLAVE: Organización del trabajo. Rio Grande. Industria naval.

\section{INTRODUÇÃO}

O trabalho é a atividade humana vital; ou seja, ao trabalhar o ser humano muda o mundo e a si mesmo simultaneamente (LUKÁCS, 2012; MARX, 2014). Apesar da conotação positiva pressuposta ao trabalho, ao nos voltarmos para o trabalho concreto é preciso REAd | Porto Alegre - Vol. 24 - No 3 - Setembro / Dezembro 2018 - p. 102-129 
compreender as contradições existentes na realidade dos trabalhadores e do trabalho no capitalismo contemporâneo (MARX, 2014).

Essa abordagem, reconhecedora das contradições entre a potência libertadora, existente no pôr teleológico materializado no trabalho (LUKÁCS, 2012), e o trabalho concreto se complexifica ao considerar o contexto no qual o trabalho ganha forma em uma economia dependente (MARINI, 1973). Consideração que foi fundamental quando, em 2014, voltamos nossa atenção para as mudanças existentes no contexto socioeconômico do município do Rio Grande, no extremo sul do Estado do Rio Grande Sul.

A decisão por parte do Governo Federal, em 2005, de implantar um Polo Naval no Município - como parte do Programa de Aceleração do Crescimento (PAC) dos governos Lula e Dilma - alterou a dinâmica socioeconômica local (SINAVAL, 2009). A instalação de estaleiros para a construção de plataformas e navios petroleiros, assim como a ampliação do porto para o embarque de soja para o mercado internacional nos davam indícios de uma mudança na condição de existência e manutenção do trabalho na cidade de Rio Grande.

Ao olhar para a história da cidade, com base no conceito de dependência (MARINI, 2012), é possível perceber como a economia local, em consonância à economia nacional, modificou a composição orgânica de seu aparato produtivo ao longo do tempo, bem como o modo como as políticas públicas brasileiras integraram o país no sistema produtivo global.

O artigo realiza, então, a articulação de ideias de Marx, Lukács e Marini de modo a construir uma análise que suportasse o entendimento sobre a forma como ocorre a organização do trabalho em Rio Grande, a partir da implementação da indústria naval. Dito de outra forma, compreender a reestruturação de um determinado espaço geográfico localizado em um país periférico, no contexto do capitalismo dependente, a partir de processos produtivos que estão fora do controle de qualquer nação individualmente ao serem definidos por interesses econômicos em escala global. Em vista disso, o objetivo central deste artigo é analisar como ocorreu a organização e reorganização do trabalho em Rio Grande no contexto de ascensão e o caso da indústria naval.

De modo a alcançar esse objetivo, foi realizada uma pesquisa qualitativa exploratória, entre 2015 e 2017, que sistematizou informações em jornais, sítios da internet, revistas e comunicações oficiais dos governos federal, estadual e municipal, empresas e sindicatos. Com esse procedimento, foi possível consolidar dados que compõem o corpus aqui analisado. O referencial teórico nos impulsionava a ter contato com os trabalhadores, tendo em vista a necessidade de compreender as contradições do trabalho na realidade local. Isso ocasionou a realização de entrevistas com trabalhadores empregados e desempregados da indústria naval, 
participação em reuniões e manifestações públicas do sindicato do ramo, e a visita às suas moradias. Foi prezado pelo tom informal das entrevistas, com registro em áudio e posterior transcrição. Os dados primários e secundários coletados foram analisados interpretativamente ao referencial teórico consolidado, primando pela compreensão das contradições que determinam e que emergem da (re)organização do trabalho no Rio Grande.

O texto está dividido nas seguintes seções temáticas: apresentação da categoria organização do trabalho; importância das políticas neodesenvolvimentistas para a implementação do polo naval; descrição do polo naval como resultado de uma estratégia para o desenvolvimento nacional; contextualização do município do Rio Grande; análise da (re)organização do trabalho no Rio Grande no ocaso da indústria naval; e, por fim, as considerações finais seguidas das referências utilizadas.

\section{ORGANIZAÇÃO DO TRABALHO}

A escolha da abordagem teórica utilizada neste texto teve por objetivo compreender o trabalho no capitalismo dependente. Não apenas em termos de processo fabril, mas focando no trabalho como fundante da práxis social; ou melhor, a ênfase está na organização da vida em determinado espaço geográfico. Neste sentido se justifica a utilização de conceitos elaborados por três autores de forma complementar: Marx (2014 [1867]) ao discorrer sobre a produção de valor posicionou o trabalho como base da reprodução da vida; Lukács (2012 [1923]), que buscou compreender as bases ontológicas do trabalho humano, entendendo o trabalho como fundante do ser e modelo da práxis social com base em elementos da teoria marxista; por último, conceitos como os de superexploração do trabalho e subimperialismo que, conforme pensados por Marini (1973), definem uma relação de articulação subordinada assumida pelos países nos quais a incorporação ao mercado global se deu prioritariamente como supridores de mão-de-obra e produtos primários e/ou de industrialização complementar ao processo capitaneado pelos países que primeiro se industrializaram.

A busca de articulação das ideias se justifica pela tentativa de construir uma análise que forneça elementos para o entendimento sobre a forma como ocorre a organização do trabalho em Rio Grande, a partir da implementação da indústria naval. Ou ainda, a reestruturação de um determinado espaço geográfico localizado em um país periférico a partir de processos produtivos que estão fora do controle de qualquer nação individualmente ao serem definidos por interesses econômicos em escala global. Neste aspecto, cabe antecipar que o processo de instalação do polo naval ocorreu de forma vinculada à identificação da 
necessidade de fornecimento de embarcações para a extração e transporte de petróleo descoberto no pré-sal, o que será melhor examinado adiante.

Ao adotar o materialismo histórico, o pressuposto assumido é de que o ser objetivo é parte movente e movida do complexo concreto que o posicionam como resultado de um processo histórico. Marx (2014), ao discorrer sobre a produção de valor, abordou a centralidade do trabalho na produção e reprodução da vida humana. Para ele, o trabalho é o elemento constituinte do ser social, assim como indispensável à sobrevivência do ser humano.

Os conceitos formulados por Marx e sua discussão sobre a produção de valor, mesmo construídas no século XIX, ainda apresentam consistente poder explicativo sobre a sociedade capitalista. Entretanto, é necessário salientar que, mesmo imersa no sistema capitalista, a cidade de Rio Grande caracteriza-se como participante de uma economia dependente latinoamericana, na qual o processo de industrialização ocorreu de maneira diferente em relação às economias centrais. Por consequência, percebeu-se a necessidade de um autor que permitisse compreender este cenário de modo amplo e crítico.

A escolha por Ruy Mauro Marini foi incontornável. Retomando algumas das categorias desenvolvidas por Marx com o objetivo de analisar o capitalismo sui generis das economias dependentes latino-americanas, ele propôs conceitos que possibilitam compreender a dependência em relação às economias centrais, como a superexploração do trabalho, o subimperialismo, a matriz agrário-exportadora e a fragilidade do mercado interno. Assim, Marini foi fundamental para compreender a dinâmica das ações e da postura do governo, além de algumas das ações das empresas, no contexto de ascensão e crise da indústria naval.

Com base nos autores acima, a organização do trabalho é definida como o resultado de uma relação de forças antagônicas dinamizada por mecanismos de produção que organizam uma forma de produzir a vida; é alterada em relação a cada ciclo econômico de acordo com uma diferente composição do capital. No caso específico de Rio Grande, os mecanismos de produção que dinamizam a relação entre trabalhadores e capitalistas, na atualidade, estão predominantemente ligados à indústria naval.

Contexto no qual, o trabalho, isto é, a "necessidade natural e eterna de efetivar o intercâmbio entre o ser humano e a natureza e, portanto, de manter a vida humana" (MARX, 2014, p. 64), “é o fenômeno originário, o modelo do ser social” (LUKÁCS, 2012, p. 35). Através do trabalho os seres humanos transcendem as questões puramente biológicas da esfera orgânica para a esfera social. Nessa transposição, a consciência assume papel central 
no por de finalidades ao trabalho, transformando o resultado do trabalho naquilo que já havia sido conscientemente ideado pelo trabalhador.

Sendo o fenômeno originário do ser social, é ele também o modelo de toda a práxis social. Somente pelo trabalho as formas fenomênicas da conduta de vida dos seres sociais emergem e, é somente a partir do trabalho que são concebidas ontologicamente (LUKÁCS, 2012). Assim, todos os aspectos da vida e da práxis social humana somente são realizáveis a partir desta que é a categoria fundante de todo o ser humano: o trabalho. Compreendendo-o desta forma, organização do trabalho significa organizar os mais diversos aspectos da vida humana, tanto na intimidade de cada indivíduo quanto da comunidade como um todo.

Com a complexificação nas formas da práxis social, o sentido originário e mais restrito do trabalho, o de interação entre ser humano e natureza, toma nova conotação, na qual há ação do ser humano sobre outros seres humanos (LUKÁCS, 2012). Quando se torna social, o trabalho depende da cooperação, isto é, depende de muitos trabalhadores atuando juntos e de acordo com um plano, no mesmo ou em diferentes processos produtivos que estejam conectados (MARX, 2014). Se, no trabalho, em seu sentido originário, o pôr teleológico tinha como conteúdo a alteração da natureza de modo a atender a uma dada carência material humana, quando o trabalho se torna social, o conteúdo essencial do pôr teleológico é o de induzir outros seres a realizarem pores teleológicos concretos (LUKÁCS, 2012).

Entretanto, a cooperação também é a forma fundamental e histórica do modo de produção capitalista (MARX, 2014). Com o processo de produção capitalista, entretanto, emergem aspectos como a necessidade de controle sobre os trabalhadores e a divisão das atividades de modo que o trabalhador não participe mais de todo o processo produtivo, como outrora, mas apenas de uma parte deste. O processo de acumulação do capital faz com que os meios de produção se transformem em formas de dominação e exploração do trabalhador que, expropriado do produto de seu trabalho, é mutilado, fragmentado, alienado de suas potencialidades espirituais e submetido a um processo de trabalho que transforma o seu tempo de vida em tempo de trabalho (MARX, 1996). Mesmo degradado pelo processo de acumulação, o trabalho continua sendo-lhe central, não como fator de criação e libertação de outrora, mas como único recurso concreto para manter o sistema capitalista em marcha.

Com o avanço da racionalização e da mecanização do trabalho sob o modo capitalista de produção, a unidade orgânica do processo de trabalho se rompe, posto que sua base está na ligação entre experiências concretas. Desse modo, a unidade do processo é dada pelo cálculo e pela análise racional, conectando arbitrariamente as operações parciais nas quais o processo 
de trabalho foi desmantelado, fazendo com que a unidade do produto como mercadoria não coincida com sua unidade como valor de uso (LUKÁCS, 2012).

O rompimento da unidade orgânica do processo de trabalho e a transformação do trabalho humano em abstração, devido ao modo de produção capitalista cada vez mais mecanizado e racionalizado, determinam a negação do ser social (DORNELAS CAMARA, 2014). Essa negação se torna mais contundente à medida que aumenta o avanço e o desenvolvimento dos mecanismos de produção do capital. Impossibilitados de sua realização como seres sociais e alienados da consciência de classe, os trabalhadores vivem uma forma negativa de produzir sua vida.

Assim, a organização do trabalho, que sob o domínio do capital tem como objetivo a extração da mais-valia, é construída de tal modo que dificulta à classe trabalhadora romper com esse sistema que mascara as relações sociais de trabalho em uma relação reificada de coisas produzidas pelo próprio trabalho humano. A consciência do trabalhador também acaba sendo reificada, e através da adoção de uma conduta meramente contemplativa, incapaz de romper com esse sistema reificado e de se reconhecer como sujeito e objeto do processo histórico (LUKÁCS, 2012).

À parte viva do capital resta a exploração de suas capacidades até o limite físico e mental. O trabalhador é explorado através da extensão das horas de trabalho para muito além do que efetivamente precisa para reproduzir sua subsistência. Tal exploração se acentua nas economias dependentes, nas quais além da exploração pelo aumento da jornada de trabalho e da intensidade do trabalho, o trabalhador tem sua remuneração reduzida abaixo do mínimo socialmente necessário para reproduzir sua subsistência (MARINI, 1973).

Assim, as implicações provocadas pela organização do trabalho ultrapassam a indústria e avançam para as casas, os bares, as famílias, enfim, às vidas dos trabalhadores e dos habitantes das cidades, posto que o trabalho é, como já analisado, o fenômeno originário e modelo da práxis social (LUKÁCS, 2012).

Neste sentido, o trabalho na cidade de Rio Grande foi constantemente organizado e reorganizado devido ao processo de acumulação do capital. Os ciclos econômicos vividos na cidade tiveram diferentes setores da indústria como protagonistas, e em cada um deles há também uma diferente composição do capital que influencia a constante (re)organização do trabalho.

Os ciclos de crescimento econômico iniciaram com uma indústria têxtil alemã, seguido por um frigorífico norte-americano, pelos incentivos do governo federal para a indústria pesqueira (MARTINS; PIMENTA, 2004), culminando na indústria naval, que 
contou com fortes incentivos governamentais e cujas empresas são controladas por consórcios nacionais e internacionais. Analisando a história da cidade, com base na ideia de dependência (MARINI, 2012), é possível perceber como a economia local, atrelada à economia nacional, modificou a composição orgânica de seu aparato produtivo ao longo do tempo, bem como o modo pelo qual as políticas públicas brasileiras integraram o país no sistema produtivo global.

Assim, a próxima parte do texto será destinada ao entendimento do contexto no qual a cidade de Rio Grande foi escolhida como espaço no qual seria implementado um polo naval com o objetivo de incentivar o desenvolvimento nacional, assim como compreender a dinâmica imposta pelo ciclo econômico atual que modificou a vida e a rotina dos trabalhadores e da comunidade nesta cidade de diferentes maneiras.

\section{A QUESTÃO DO DESENVOLVIMENTO NACIONAL}

No período que o Partido dos Trabalhadores (2003-2016) esteve à frente do Governo Federal Brasileiro predominaram práticas ligadas ao incentivo do desenvolvimento nacional, suportado predominantemente por ideias defensoras do novo desenvolvimentismo (BRESSER-PEREIRA, 2006). Neste sentido, a presidenta Dilma Rousseff, ao suceder o expresidente Lula, reafirmou como ponto fundamental de sua agenda e, principalmente, como base para os projetos e programas que seriam estimulados em seu governo a necessidade de crescimento econômico; e com ele de estabilidade macroeconômica e de controle da inflação. O foco na capacidade de exportação ficou em evidência como meio de equilibrar a balança comercial, assim como o consequente estímulo à competitividade dos produtos nacionais, tanto no mercado interno como no externo (ROUSSEFF, 2011).

No último aspecto ganhou relevância o papel do Estado como indutor do investimento privado, razão pela qual o “[...] PAC [Plano de Aceleração do Crescimento] continuará sendo um instrumento de coesão da ação governamental e coordenação voluntária dos investimentos estruturais dos estados e municípios. Será também vetor de incentivo ao investimento privado [...]" (ROUSSEFF, 2011, s/p.).

O Estado aparece, ainda, com um papel de planejamento estratégico que busca facilitar a relação entre mercado e governo, com vista ao crescimento que estaria na base do estímulo às políticas sociais, sendo com “[...] crescimento, associado a fortes programas sociais, que venceremos a desigualdade de renda e do desenvolvimento regional" (ROUSSEFF, 2011, s/p.).

REAd | Porto Alegre - Vol. 24 - No 3 - Setembro / Dezembro 2018 - p. 102-129 
Por consequência, os aspectos determinantes das estratégias políticas do governo brasileiro que vigoravam afirmavam que a melhoria das condições de vida da população dependeriam do desempenho econômico, de forma semelhante à releitura proposta pelos neodesenvolvimentistas; com a ressalva feita por alguns autores de que existia à época uma preocupação em focar as atenções na melhoria das condições de vida (RANDS, 2010; MERCADANTE, 2010).

É importante salientar, também, a preocupação com a formação de um mercado consumidor interno que fomentasse o crescimento do parque fabril. Entretanto, no que se relaciona à estratégia, o foco se direcionou para a capacidade de articulação com o mercado internacional e com a possibilidade de produção de produtos competitivos tanto em nível interno como externo (BRESSER-PEREIRA, 2006; MERCADANTE, 2010; RANDS, 2010).

Mesmo em relação à capacidade de consumo, as políticas públicas desenvolvidas a partir de 2003 definiram prioritariamente práticas ligadas ao fomento do consumo interno como meios para indução do investimento privado, através da democratização do acesso ao crédito, da implementação de programas sociais de transferência de renda e de grandes obras de infraestrutura - neste último caso entram as obras do PAC e, entre elas, as vinculadas ao Superporto do Rio Grande (BRASIL, 2012).

\section{O PLANO DE ACELERAÇÃO DO CRESCIMENTO (PAC) E O SUPERPORTO}

Visando o incentivo ao crescimento econômico, o diagnóstico feito pelo Governo Federal identificou, em escala nacional, pontos de estrangulamento: infraestrutura insuficiente (principalmente em termos de transporte e energia) e baixo nível de crédito e financiamento aos investimentos (BRASIL, 2012).

Objetivando a redução das dificuldades observadas em relação à infraestrutura foram atribuídos três focos prioritários aos investimentos do PAC: (1) logística, com a ampliação de rodovias, ferrovias, portos, aeroportos e hidrovias; (2) energia, que implica melhoria na produção e fornecimento de energia elétrica, petróleo, gás e combustíveis renováveis; (3) área social e urbana, que envolve melhoria nas condições de vida para a população (BRASIL, 2007; 2012).

A definição dos objetivos citados aliada a um contexto no qual foi descoberta grande quantidade de petróleo em águas profundas gerou demanda em termos de maior quantidade de bases e embarcações de apoio para a extração e o transporte de petróleo. Razão pela qual o 
Governo Federal decidiu incentivar o fortalecimento da indústria naval no Brasil (SINAVAL, 2009).

A importância econômica do Porto do Rio Grande e sua posição estratégica possibilitaram sua inclusão em programas do governo nacional - Programa de Aceleração do Crescimento (PAC) e na recuperação da indústria naval - provocando, assim, alteração estrutural na cidade no início do século XXI (SINAVAL, 2009).

Cabe destacar que os investimentos realizados no polo naval e no Superporto do Rio Grande estiveram vinculados a um conjunto de medidas que almejavam elevar as taxas de crescimento econômico do país e foram operacionalizados por meio de parcerias com instituições privadas. Fato que é facilmente verificável ao observar os estaleiros que se instalaram na cidade, entre eles: Quip, em 2009, resultado da associação de grandes empreiteiras privadas entre elas Queiroz Galvão e Camargo Correa; e ECOVIX, em 2010, que foi viabilizado pela associação entre uma empresa de engenharia especializada em empreendimentos nas áreas de energia, indústria e infraestrutura e um fundo de investimentos (JORNAL AGORA, 2015). Postura que reforça uma estratégia governamental que buscava fomentar o investimento privado.

Assim, o polo naval do Rio Grande emergiu como resultado de uma estratégia nacional de desenvolvimento que buscava aproveitar os potenciais locais e que possuía como um de seus objetivos a descentralização do crescimento, razão pela qual o investimento governamental feito na cidade atraiu grandes empresas interessadas na atividade petrolífera do Brasil. Atração de capital que foi fomentada, em parte, por uma política governamental que impôs que percentual dos componentes utilizados na construção de plataformas e navios petrolíferos fosse de produção nacional (SINAVAL, 2009).

Em relação à cidade do Rio Grande, no período que iniciou com a decisão por parte do governo federal de implantação de um polo naval, foram percebidas alterações na geração de emprego e renda, com o aumento significativo dos postos de trabalho. Neste aspecto, as informações divulgadas à época na mídia local referiam que cada contrato efetivado para a construção de plataformas se traduziria em 3.500 vagas de trabalho em apenas um dos estaleiros (JORNAL AGORA, 2015). Informação que tornava objetiva a percepção de vários dos moradores da cidade entrevistados, segundo os quais a cidade estava, à época, sendo transformada em seu perfil.

Entretanto, a dinâmica socioeconômica do município está vinculada ao comércio nacional e internacional de mercadorias que são escoadas pelo porto e, no que tange ao polo naval, predominava o foco ligado à construção de embarcações para a extração e transporte 
de produto natural (petróleo) que tem por destino o mercado global. No que se refere ao movimento de produtos pelo Porto do Rio Grande foi registrado um volume de 17.988.926 toneladas no primeiro semestre de 2014, o maior no período entre 2006 e 2014 . No mesmo semestre, as exportações apresentaram um volume de 8.932 .185 toneladas das quais $47,5 \%$ teve como destino a China (RIO GRANDE DO SUL, 2015). Portanto, o processo de desenvolvimento predominante na cidade está vinculado à permanência de interesse econômico externo, sobre o qual a cidade exerce pouca influência (CARVALHO; CARVALHO; DOMINGUES, 2012).

Neste sentido, de forma a reproduzir os mecanismos ligados a um padrão de divisão internacional do trabalho que delega às nações subdesenvolvidas atividades complementares àquelas vigentes nos países dinamizadores do processo de crescimento, os aspectos que fomentam o desenvolvimento socioeconômico da cidade são dados por fatores exógenos.

Fato que, por um lado, caracteriza uma forma de desenvolvimento dependente da dinâmica global; por outro, tal processo de desenvolvimento é planejado e institucionalizado a partir de políticas públicas vinculadas a uma estratégia de facilitação do investimento privado, no qual os sujeitos inseridos no espaço alvo dos investimentos têm pouco poder de influência.

Cabe salientar, entretanto, que o fomento externo necessita estar organicamente articulado às práticas e crenças locais, razão pela qual serão apresentadas a seguir algumas das características histórico-sociais do munícipio que facilitaram sua integração às políticas nacionais e práticas globais.

\section{O MUNICÍPIO DE RIO GRANDE}

O município de Rio Grande faz parte da chamada Metade Sul, que ocupa mais da metade do território do Rio Grande do Sul (54\%), possui 25\% da população e 18\% do PIB. Entre seus maiores e principais municípios estão: Rio Grande, Pelotas, Santa Maria, Bagé e Sant'Ana do Livramento (RIO GRANDE DO SUL, 2018; FUNDAÇÃO INSTITUTO BRASILEIRO DE GEOGRAFIA E ESTATÍSTICA, 2018).

A Metade Sul apresenta uma situação peculiar, já que no decorrer da evolução histórica e apesar da industrialização centralizada em Rio Grande e Sant'Ana do Livramento e desencadeada no período entre guerras, a estrutura socioeconômica delineou-se predominantemente com base na pecuária e posteriormente na agricultura (MARTINS; PIMENTA, 2004).

REAd | Porto Alegre - Vol. 24 - No 3 - Setembro / Dezembro 2018 - p. 102-129 
A cidade do Rio Grande é a mais antiga do Estado do Rio Grande do Sul, tendo sido fundada em 1737 como uma fortificação portuguesa. No período que se seguiu a sua fundação, a vila serviu de passagem às embarcações que faziam o trajeto entre o centro do Brasil e a Colônia de Sacramento, no Uruguai. Pela sua posição estratégica tornou-se um espaço geográfico disputado entre espanhóis e portugueses que tinham por finalidade o controle da Colônia do Sacramento - estrategicamente localizada em frente a Buenos Aires. Por consequência, o espaço geográfico onde se localiza a cidade de Rio Grande pertenceu aos Espanhóis de 1763 a 1776 (MARTINS; PIMENTA, 2004).

Posteriormente, com o enriquecimento dos criadores de gado da campanha - em função da introdução das charqueadas -, a Vila do Rio Grande ganhou o status de cidade e em 1835, na eclosão da Revolução Farroupilha, voltou a se tornar capital do Estado, já que possuía o único porto marítimo do Rio Grande do Sul. Aquele período foi de expansão do comércio ligado à importação e exportação, de forma que a cidade cresceu de maneira contínua e criou as condições para a emergência do processo de industrialização que perdurou até a década de 1960 (COPSTEIN, 1975).

Cabe salientar que a industrialização gaúcha, em seu início, localizou-se entre as cidades de Rio Grande e Pelotas, já que as indústrias, assim como os produtores de charque da região visavam mercados mais amplos existentes no centro do país e no exterior, o que tornava a proximidade com o porto de Rio Grande uma condição muitas vezes indispensável (MARTINS; PIMENTA, 2004).

No período de 1910 a 1930 foram abertas novas possibilidades ao processo de crescimento. Aquele período iniciou com a construção de um novo porto na cidade que tinha por objetivo facilitar a passagem de navios entre o Oceano Atlântico e a Lagoa dos Patos e foi acompanhado por investimentos ligados ao fornecimento de energia elétrica ao porto e parte da cidade. Para estas obras foram contratados técnicos europeus e norte-americanos (MARTINS; PIMENTA, 2004; COSTA, 1922).

Naquele mesmo período, em resposta à decadência das charqueadas, teve início o processo de industrialização da carne no Rio Grande do Sul. Processo que inicialmente deveria ser desenvolvido com capital dos próprios criadores; entretanto, o governo estadual permitiu a entrada de capital estrangeiro com o objetivo de modernizar tecnologicamente a produção pecuária (PESAVENTO, 1990). Fato que facilitou a implantação de frigoríficos estrangeiros no Rio Grande do Sul, como as indústrias Wilson e Armour em Sant'Ana do Livramento e Swift em Rio Grande. 
Com a situação contextual em escala global (início da $1^{\mathrm{a}}$ guerra em 1914), o frigorífico Swift, de capital norte-americano, rapidamente se constituiu em importante ator econômico. Cabe salientar que naquele período o processo de industrialização ganhou vigor com o crescimento das indústrias existentes e a implantação de novas indústrias alimentícias, entre elas as de pescados.

Em termos de infraestrutura, em 1915 a iluminação a gás começou a ser substituída pela elétrica e o transporte público passou a ser realizado através de bondes elétricos. Já, na década de 1920 surgiu a primeira linha postal aérea e a primeira linha aérea comercial do Brasil que ligavam Rio Grande a Porto Alegre (MARTINS; PIMENTA, 2004).

Na década de 1930 iniciou em escala nacional a Era Vargas, na qual o país começou a buscar uma forma de desenvolvimento industrial própria com estímulo ao processo de substituição de importações. Processo no qual o parque fabril de São Paulo tomou a dianteira (CANO, 1985). Entretanto, a industrialização de Rio Grande ganhou sobrevida com a grande depressão de 1929 e com a Segunda Guerra (1939-1945) que provocou a manutenção de altos níveis de demanda externa, apesar da redução do mercado consumidor interno. Ainda na segunda metade da década de 1930 é instalada a refinaria de petróleo Ipiranga como resultado de uma das poucas transposições do capital agrário para o industrial na região, consequência da associação de capitais dos fazendeiros de Uruguaiana, do Uruguai e da Argentina (PESAVENTO, 1985).

A indústria pesqueira também se fortaleceu durante o período em resultado de financiamentos proporcionados pelo Governo Federal que auxiliaram a consolidar o setor de pescados de forma pioneira no País, de tal forma que vieram, junto com as empresas de conservas alimentícias, a se tornarem base do dinamismo industrial da região a partir da segunda metade do século XX, período em que as indústrias têxteis e os frigoríficos passaram a enfrentar dificuldades e muitas encerraram as atividades na cidade (MARTINS; PIMENTA, 2004).

No que tange às indústrias têxteis, os frigoríficos e outras de grande porte ao enfrentarem problemas e encerrarem muitas das linhas de produção provocaram crise local com a diminuição de, aproximadamente, 7 mil vagas de trabalho em uma população total de 82 mil habitantes. O que afetou sensivelmente a dinâmica municipal (SALVATORI et al., 1989).

Situação que se estendeu sem alterações significativas até a década de 1970, quando ocorreu o início da construção do Superporto e do distrito industrial destinado à instalação de indústrias e prestadoras de serviços portuários. O distrito industrial é administrado pelo 
Governo do Estado do Rio Grande do Sul e nele se estabeleceram empresas de setores como metalurgia, fertilizantes, serviços, alimentos, madeiras, energia e química (RIO GRANDE DO SUL, 2018).

\section{O CONTEXTO ATUAL}

Como visto anteriormente, os ciclos econômicos vividos na cidade de Rio Grande periodicamente alteraram a organização de seu espaço geográfico. Desde sua fundação, como um entreposto às embarcações que se dirigiam do centro-sul do Brasil para a Colônia de Sacramento, passando pelo processo de industrialização que perdurou da década de 1870 até a de 1960, o ciclo pesqueiro na década de 1970, de revalorização das atividades portuárias (a partir da década de 1990), até o recente processo de criação e declínio do polo naval, o Município tem visto suas iniciativas direcionadas ao crescimento econômico caracterizaremse por sua origem exógena.

A constante percepção de que as possibilidades abertas ao Munícipio estão vinculadas aos investimentos externos feitos na região suscita na população expectativas de que novos investimentos vindouros são a alternativa para a dissolução dos problemas gerados pelas crises cíclicas. Entretanto, é desconsiderado que os momentos de bonança, assim como as crises periódicas, são resultado de um mesmo processo que se utiliza do potencial de trabalho local ou migratório como recurso com vista à manutenção e, principalmente, lucratividade dos investimentos externos.

O resultado observável, na cidade, é a transformação periódica da vida da população local em decorrência da (re)organização do trabalho. Ou seja, é a classe trabalhadora que precisa constantemente adaptar-se à novas exigências, aos novos setores produtivos e até mesmo as novas profissões. Evidentemente, como resultado, a população riograndina como um todo necessita alterar seu cotidiano, adequando-o aos ciclos econômicos da cidade.

O mais recente ciclo econômico de Rio Grande que iniciou com a implementação da indústria naval, atualmente se encontra em crise. Embora, em alguns aspectos, não destoe dos ciclos que o precederam, sua chegada trouxe novos constituintes ao dia a dia local. $\mathrm{O}$ que parecia ser algo distante antes da crise da indústria naval, isto é, o encerramento das atividades do setor em Rio Grande, passou a ser uma realidade próxima e factível. As incertezas quanto à continuidade do setor e, se permanecer, ao volume de produção em que operará, movimentaram ainda mais o cotidiano já bastante atribulado da população de Rio Grande. 
Cabe neste ponto, relembrar que o conceito de organização do trabalho é entendido neste texto como o resultado de uma relação de forças antagônicas dinamizada por mecanismos de produção que organizam formas de produzir a vida. É necessário, ainda, explicitar que tais formas de produção da vida são, primeiro, resultado de relações objetivas que possibilitam a vida em determinado contexto. Assim, a vida é construída e alterada a cada novo ciclo econômico de acordo com o resultado dessa relação de forças (MARX, 2013).

No que se refere às estatísticas sobre a cidade de Rio Grande, no período entre $2006 \mathrm{e}$ 2012, se observa o aumento da arrecadação municipal, do número de empregos e da média salarial (IBGE, 2018). Entretanto, expressavam também a condição de recurso de produção ocupada pelo trabalhador, que vende sua força de trabalho, sua individualidade viva ao capitalista, conforme proposto anteriormente por Marx (2006).

A aparente prosperidade ganhou força com o crescimento de $157,7 \%$ do PIB de Rio Grande no período 2006-2012. Sendo que 2012 foi o ano que o munícipio alcançou o melhor resultado até o momento atual (Tabela 1).

Tabela 1 - Evolução do PIB de Rio Grande no período de 2006 e 2015

\begin{tabular}{c|c|c}
\hline Ano & PIB & PIB per capita \\
\hline $\mathbf{2 0 0 6}$ & 3.477 .887 .723 & 17.656 \\
\hline $\mathbf{2 0 0 7}$ & 4.442 .147 .349 & 22.856 \\
\hline $\mathbf{2 0 0 8}$ & 6.302 .581 .400 & 32.225 \\
\hline $\mathbf{2 0 0 9}$ & 6.372 .569 .216 & 32.457 \\
\hline $\mathbf{2 0 1 0}$ & 7.778 .545 .750 & 39.439 \\
\hline $\mathbf{2 0 1 1}$ & 8.193 .203 .273 & 41.369 \\
\hline $\mathbf{2 0 1 2}$ & 8.965 .447 .462 & 45.088 \\
\hline $\mathbf{2 0 1 3}$ & 8.147 .934 .388 & 39.522 \\
\hline $\mathbf{2 0 1 4}$ & 7.357 .681 .054 & 35.538 \\
\hline $\mathbf{2 0 1 5}$ & 7.274 .579 .588 & 34.997 \\
\hline
\end{tabular}

Fonte: Fundação de Economia e Estatística Siegfried Emanuel Heuser (2017).

Entretanto, mesmo com o aumento do PIB, o índice de Gini não apresentou variação significativa, passando de 0,5381 em 1991 para 0,5248 em 2010 (Tabela 2). Neste período de 20 anos, parece que o "bolo cresceu", mas sua partilha continua desigual. 
Tabela 2- Índice de Gini da Renda Domiciliar Per Capita em Rio Grande entre 19912010

Fonte: Departamento de Informática do Sistema Único de Saúde (2017).

\begin{tabular}{c|c|c|c}
\hline Ano & $\mathbf{1 9 9 1}$ & $\mathbf{2 0 0 0}$ & $\mathbf{2 0 1 0}$ \\
\hline Índice de Gini & 0,5381 & 0,5676 & 0,5248 \\
\hline
\end{tabular}

Cabe destacar que foi observado equilíbrio nos níveis de participação dos diferentes setores da economia na composição do PIB de Rio Grande, mesmo com a indústria naval como "protagonista da prosperidade", o que pode ser explicado pelo crescimento do número Micro e Pequenas Empresas (MPEs) e de Micro Empreendedores Individuais (MEI). Ao longo do período de 2001-2015, o número de MPEs na cidade mais que dobrou, apresentando um aumento de 104,1\%. A participação das MPEs no total de empresas instaladas no município passou de 93\% em 2007, para 95\% em 2015, com mais de 50\% das MPEs concentradas nas áreas de comércio e serviços (Confederação Nacional do Comércio de Bens, Serviços e Turismo, 2015).

Outro dado a cerca dos pequenos empreendimentos que merece destaque é o número de Microempreendedores Individuais (MEI) na cidade. Em 2009, havia 108 MEI registrados em Rio Grande. Já em 2016, o número passou para 5.158, o que representa um crescimento de mais de $4.000 \%$ em sete anos (PORTAL DO EMPREENDEDOR, 2017). Embora o crescimento total no período apresente números impactantes, o crescimento vem caindo gradativamente, como demonstra a Tabela 3.

Tabela 3 - Microempreendedores Individuais em Rio Grande entre 2009-2016

Fonte: Portal do Empreendedor (2017).

\begin{tabular}{r|l|l|r}
\hline Ano & \multicolumn{1}{|c|}{ Total } & \multicolumn{2}{|c}{$\%$ Crescimento } \\
\hline $\mathbf{2 0 0 9}$ & 108 & $\mathbf{2 0 1 0 / 2 0 0 9}$ & $720,4 \%$ \\
\hline $\mathbf{2 0 1 0}$ & 886 & $\mathbf{2 0 1 1 / 2 0 1 0}$ & $84,7 \%$ \\
\hline $\mathbf{2 0 1 1}$ & 1.636 & $\mathbf{2 0 1 2 / 2 0 1 1}$ & $54,8 \%$ \\
\hline $\mathbf{2 0 1 2}$ & 2.533 & $\mathbf{2 0 1 3 / 2 0 1 2}$ & $33,4 \%$ \\
\hline $\mathbf{2 0 1 3}$ & 3.380 & $\mathbf{2 0 1 4 / 2 0 1 3}$ & $24,2 \%$ \\
\hline $\mathbf{2 0 1 4}$ & 4.199 & $\mathbf{2 0 1 5} / \mathbf{2 0 1 4}$ & $17,4 \%$ \\
\hline $\mathbf{2 0 1 5}$ & 4.929 & $\mathbf{2 0 1 5} / \mathbf{2 0 1 6}$ & $4,64 \%$ \\
\hline $\mathbf{2 0 1 6}$ & 5.158 & $\mathbf{2 0 1 6} / \mathbf{2 0 0 9}$ & $4675,9 \%$ \\
\hline
\end{tabular}

Dos 4.929 MEI registrados em Rio Grande no ano de 2015, 30\% deles, ou seja, 1.486 estão inscritos no Cadastro Único do município (BRASIL, 2015a). O fato de tantos MEI 
estarem registrados no Cadastro Único em Rio Grande aparenta que a formalização do trabalhador informal é apenas uma forma de mascarar números e indicadores de emprego e renda no Brasil, reforçando a superexploração do trabalhador.

Cabe destacar que os Microempreendedores Individuais são pessoas que trabalham por conta própria, trabalhadores informais, que a partir da Lei Complementar $n^{\circ}$ 128/2008 tem a possibilidade de legalizarem suas atividades como pequenos empresários (PORTAL DO EMPREENDEDOR, 2017). O MEI, tendo em vista o referencial teórico adotado neste texto, é uma alternativa do mercado para os trabalhadores informais ao exército de reserva. Esta alternativa melhora os indicadores de emprego e renda do governo, mas reforça os mecanismos de superexploração do trabalho.

Em se tratando de emprego e renda, o campo do emprego foi um dos mais impactados pela instalação da indústria naval em Rio Grande. O crescente número de postos de trabalho na cidade, fruto da instalação da indústria naval e do crescimento da cidade por ela provocado, como já mencionado anteriormente, atraiu para Rio Grande um número significativo de trabalhadores de outras regiões do país. Alguns destes trabalhadores chegaram à cidade para ocupar postos de trabalho específicos (SILVA et al, 2012), devido a sua qualificação, enquanto outros simplesmente na esperança de um emprego. Entre 2013 e 2014, cerca de 15.000 trabalhadores oriundos de outras regiões do país residiam em Rio Grande (PINTO, 2014). Este número correspondia a aproximadamente 7\% da população da cidade de Rio Grande estimada pelo IBGE.

De 2007 a 2013 (ano de maior volume de produção da indústria naval), houve crescimento significativo no número de admissões, como evidenciam as Tabelas 4 e 5 . A variação absoluta do número de admissões e demissões registrados em Rio Grande demonstra o movimento de trabalhadores que são absorvidos e lançados ao exército industrial de reserva a cada ano.

Tabela 4 - Admissões e Demissões no Rio Grande de 2007-2016

\begin{tabular}{c|c|c|c}
\hline Ano & Admissões & Desligamentos & Variação Absoluta \\
\hline $\mathbf{2 0 0 7}$ & 11.942 & 10.455 & 1.487 \\
\hline $\mathbf{2 0 0 8}$ & 13.566 & 12.693 & 873 \\
\hline $\mathbf{2 0 0 9}$ & 12.852 & 12.213 & 639 \\
\hline $\mathbf{2 0 1 0}$ & 16.689 & 14.380 & 2.309 \\
\hline $\mathbf{2 0 1 1}$ & 20.360 & 17.408 & 2.952 \\
\hline $\mathbf{2 0 1 2}$ & 31.572 & 24.830 & 6.742 \\
\hline $\mathbf{2 0 1 3}$ & 41.773 & 41.290 & 483 \\
\hline $\mathbf{2 0 1 4}$ & 33.172 & 32.271 & 901 \\
\hline
\end{tabular}

REAd | Porto Alegre - Vol. 24 - No 3 - Setembro / Dezembro 2018 - p. 102-129 


\begin{tabular}{l|l|l|l}
\hline $\mathbf{2 0 1 5}$ & 10.408 & 11.722 & -1.314 \\
\hline $\mathbf{2 0 1 6}$ & 15.794 & 20.803 & -5.009 \\
\hline
\end{tabular}

Fonte: Brasil (2017).

Os anos de 2010, 2011 e 2012 foram os que apresentaram as maiores variações absolutas positivas do período. Embora o número de empregos gerados tenha aumentado substancialmente nesse período, os desligamentos cresceram em proporções semelhantes, ambos provavelmente impulsionados pela constante movimentação e troca de empregos ocorrida, sobretudo, na indústria naval. Na série observada, os únicos anos a apresentar variação absoluta negativa foram 2015 e 2016, evidenciando os efeitos da crise em Rio Grande. O setor de serviços liderou o número de desligamentos de trabalhadores na cidade em 2015, com um total de 4.174 demissões, seguido do Comércio, com 3.744, e da Indústria de Transformação, com 2.627 demissões (BRASIL, 2017).

Tabela 5 - Variação \% das Admissões e Demissões em Rio Grande

\begin{tabular}{l|c|c|c|c|c|c|c|c}
\hline \multicolumn{1}{c|}{ Ano } & $\begin{array}{c}\mathbf{2 0 0 8} / \\
\mathbf{2 0 0 7}\end{array}$ & $\begin{array}{c}\mathbf{2 0 0 9 /} \\
\mathbf{2 0 0 8}\end{array}$ & $\begin{array}{c}\mathbf{2 0 1 0} / \\
\mathbf{2 0 0 9}\end{array}$ & $\begin{array}{c}\mathbf{2 0 1 1} / \\
\mathbf{2 0 1 0}\end{array}$ & $\begin{array}{c}\mathbf{2 0 1 2} / \\
\mathbf{2 0 1 1}\end{array}$ & $\begin{array}{c}\mathbf{2 0 1 3} / \\
\mathbf{2 0 1 2}\end{array}$ & $\begin{array}{c}\mathbf{2 0 1 4} / \\
\mathbf{2 0 1 3}\end{array}$ & $\begin{array}{c}\mathbf{2 0 1 4} / \\
\mathbf{2 0 0 7}\end{array}$ \\
\hline Admissões & $13,6 \%$ & $-5,3 \%$ & $29,9 \%$ & $22,0 \%$ & $55,1 \%$ & $32,3 \%$ & $-20,6 \%$ & $177,8 \%$ \\
\hline Desligamentos & $21,4 \%$ & $-3,8 \%$ & $17,7 \%$ & $21,1 \%$ & $42,6 \%$ & $66,3 \%$ & $-21,8 \%$ & $208,7 \%$ \\
\hline $\begin{array}{l}\text { Variação } \\
\text { Absoluta }\end{array}$ & $-41,3 \%$ & $-26,8 \%$ & $261,3 \%$ & $27,8 \%$ & $128,4 \%$ & $-92,8 \%$ & $86,5 \%$ & $-39,4 \%$ \\
\hline
\end{tabular}

Fonte: Elaborado pelos autores.

Dados do Sindicato Nacional da Indústria da Construção e Reparo Naval e Offshore (SINAVAL) demonstram uma redução significativa no número de trabalhadores empregados na indústria naval brasileira nos anos de 2015 e 2016, em comparação a 2014. Houve uma redução de 3.469 empregos somente em Janeiro de 2015. Em Março e Junho de 2015, as reduções chegaram a 10.406 e 14.472, respectivamente (SINDICATO NACIONAL DA INDÚSTRIA DA CONSTRUÇÃO E REPARO NAVAL E OFFSHORE, 2015). O dado de Junho demonstra uma redução de $17,5 \%$ no total de trabalhadores empregados na indústria naval somente em 2015. Em Rio Grande, somente no mês de dezembro de 2016, em função da conclusão de uma das plataformas e pelo contexto de incertezas, foram demitidos 3.200 trabalhadores $(\mathrm{ZH}, 2017)$. A Tabela 6 apresenta o número de trabalhadores empregados na indústria no período 2005-2015.

Tabela 6 - Flutuação do Emprego na Indústria Naval nos últimos de 2005 a 2015 


\begin{tabular}{c|c|c|c|c|c|c|c|c|c|c|c}
\hline $\begin{array}{c}\text { Mês de } \\
\text { Referência }\end{array}$ & $\mathbf{2 0 0 5}$ & $\mathbf{2 0 0 6}$ & $\mathbf{2 0 0 7}$ & $\mathbf{2 0 0 8}$ & $\mathbf{2 0 0 9}$ & $\mathbf{2 0 1 0}$ & $\mathbf{2 0 1 1}$ & $\mathbf{2 0 1 2}$ & $\mathbf{2 0 1 3}$ & $\mathbf{2 0 1 4}$ & $\mathbf{2 0 1 5}$ \\
\hline Janeiro & 14.442 & 19.600 & 29.125 & 33.277 & 40.500 & 56.112 & 59.167 & 62.036 & 78.136 & 82.472 & 79.003 \\
\hline
\end{tabular}

Fonte: Sindicato Nacional da Indústria da Construção e Reparo Naval e Offshore (2015).

O número total de trabalhadores empregados nos estaleiros do RS, em Janeiro de 2015, correspondeu a 9,2\% do total da indústria naval brasileira. A trajetória do emprego nos estaleiros gaúchos apresenta, desde 2009, um crescimento constante cujo ápice foi no ano de 2013, quando correspondia a 25,5\% do total de empregos no setor. Após a crise da indústria naval, esse número caiu pela metade em 2014, ficando em 11,8\%, até chegar aos 9,2\% no começo de 2015 (SINDICATO NACIONAL DA INDÚSTRIA DA CONSTRUÇÃO E REPARO NAVAL E OFFSHORE, 2015). A Tabela 7 apresenta esses números mais detalhadamente.

Tabela 7 - Número de Empregos nos Estaleiros do RS (2009-2015)

\begin{tabular}{l|r|r|r|r|r|r|r}
\cline { 2 - 8 } & $\mathbf{2 0 0 9}$ & $\mathbf{2 0 1 0}$ & $\mathbf{2 0 1 1}$ & $\mathbf{2 0 1 2}$ & $\mathbf{2 0 1 3}$ & $\mathbf{2 0 1 4}$ & $\mathbf{2 0 1 5}$ \\
\hline RS & 820 & 5.500 & 5.500 & 6.174 & 19.954 & 9.762 & 7.259 \\
\hline Total Nacional & 40.500 & 56.112 & 59.167 & 62.036 & 78.136 & 82.472 & 79.003 \\
\hline $\begin{array}{l}\text { \% Participação } \\
\text { RS }\end{array}$ & $2,0 \%$ & $9,8 \%$ & $9,3 \%$ & $10,0 \%$ & $25,5 \%$ & $11,8 \%$ & $9,2 \%$ \\
\hline
\end{tabular}

Fonte: Sindicato Nacional da Indústria da Construção e Reparo Naval e Offshore (2015).

Os salários médios pagos aos trabalhadores também sofreram com a crise econômica em que o país se encontra. Em Rio Grande, o salário médio de admissão sofreu uma queda de 2,7\% em relação a 2014, com destaque para os setores da Construção Civil e Indústria de Transformação, com quedas de 17,8\% e 16,3\%, respectivamente. A remuneração paga a um trabalhador que executa a atividade de Soldador sofreu uma redução de $27,2 \%$ em 2015, se comparada a 2014 , e de $31,4 \%$ se comparada a 2013 , ano do maior volume de produção da indústria naval em Rio Grande (BRASIL, 2017).

De forma a ratificar as afirmações de Marx (1996), esses números evidenciam a posição de recurso produtivo ocupada pelos trabalhadores, que são contratados e liberados, de acordo com as necessidades do processo de acumulação do capital. A acumulação do capital multiplica a demanda de trabalho ao mesmo tempo em que multiplica a oferta de trabalhadores. $\mathrm{O}$ crescente exército industrial de reserva, neste período de crise, pressiona os trabalhadores empregados a intensificarem seus esforços e a aceitarem remunerações menores, como os números apresentados anteriormente demonstraram. 
Não apenas os números evidenciam essa posição ocupada pelos trabalhadores. O tratamento dispensado a eles também reflete essa realidade. Parte do grande contingente de trabalhadores migrantes que desembarcaram em Rio Grande nos últimos anos em busca de emprego na indústria naval, enfrenta uma realidade bem menos colorida do que a apresentada nos discursos e números oficiais de prosperidade. Dados primários coletados com pessoas ligadas a Secretaria de Município de Cidadania e Assistência Social (SMCAS) indicam que alguns dos alojamentos onde grande parte dos trabalhadores migrantes estava hospedada, apresentavam risco à vida e a integridade física das pessoas ali hospedadas. A degradação da condição do trabalhador se dá tanto pelos aspectos de infraestrutura e saneamento dos locais, quanto pela forma como os proprietários dos alojamentos agem em relação a seus inquilinos (ÁVILA, 2014).

Um dos relatos mais chocantes feito pelos entrevistados foi das chamadas "quentinhas". A “quentinha" é o nome dado à cama que é alugada para mais de um trabalhador. Considerando que os trabalhadores do polo naval trabalham em turno, os ocupantes da "quentinha" tinham direito ao uso da cama no seu turno de folga. Os alojamentos que realizavam esta prática alugavam para dois trabalhadores a mesma cama, aumentando seus ganhos e favorecendo-se do fato de que muitos deles se encontravam sem condições financeiras para pagarem valores mais altos de aluguel e acabavam, sem alternativa, submetendo-se a esta prática.

Alguns alojamentos espalhados pela cidade colocam em risco a vida e a integridade física dos trabalhadores ali hospedados. Em 2013, dois desses locais foram atingidos por incêndios. O primeiro deles, em um prédio ocupado por 60 trabalhadores, ocorreu em março e foi provocado por um curto circuito. Os ocupantes que estavam no prédio no momento do incêndio saíram com ferimentos leves, embora sem conseguir salvar seus pertences (JORNAL AGORA, 2013). O segundo incêndio, no mês de junho, foi provocado por uma vela acesa. A casa convertida em alojamento estava sem energia elétrica havia cerca de 7 dias, por irregularidades constatadas na fiação e que, até aquele momento, não tinham sido corrigidas (POLL, 2013a).

Os problemas de infraestrutura dos alojamentos não se restringiram à rede de energia elétrica. No "Carandiru", as dificuldades enfrentadas pelos trabalhadores foram muitas. O

\footnotetext{
5 Nome dado em alusão à Casa de Detenção de São Paulo, popularmente conhecida como Carandiru. A casa de detenção, inaugurada nos anos 1920, chegou a ser considerado o maior presídio da América Latina nos anos 1990, quando abrigava cerca de oito mil detentos. Um dos fatos de maior repercussão em sua história foi o "Massacre do Carandiru", em 1992, quando mais de cem detentos foram mortos pela Polícia Militar do Estado de São Paulo durante uma rebelião.
}

REAd | Porto Alegre - Vol. 24 - No 3 - Setembro / Dezembro 2018 - p. 102-129 
prédio, ocupado por cerca de 200 pessoas de 3 empresas diferentes no ano de 2013, é composto por dois blocos fechados, com dois pavimentos cada, um de frente para o outro, com um pequeno corredor separando-os. Poll (2013b) descreve que os quartos são pequenos, ocupados por até quatro homens, sem boa posição solar, úmidos e com proliferação de mofo pelas paredes e teto. O prédio recebeu o nome de "Carandiru" devido ao estreito corredor que separa os dois blocos que é repleto de varais de roupa, porque, segundo os trabalhadores, é impossível secar as roupas dentro dos quartos.

O desrespeito ao trabalhador e a superexploração do trabalho também são encontrados nos dados primários coletados com pessoas ligadas ao Sindicato dos Trabalhadores das Indústrias Metalúrgicas e de Material Elétrico de Rio Grande e São José do Norte (STIMMMERG). Os relatos indicam, por exemplo, a permanência nas dependências da empresa contratante de trabalhadores que sofreram acidente de trabalho, com o intuito de não prejudicar os indicadores de segurança. Nesses casos, a empresa buscava os trabalhadores nas suas casas no horário de expediente e estes permaneciam em uma sala aguardando a hora de voltar para casa.

Outro aspecto relevante no que concerne à influência das alterações sentidas no cotidiano da cidade se refere ao aumento dos aluguéis, que corrigidos pelo INPC passaram, em média, de R\$625,32 em 2000 para R\$ 841,05 em 2010 (BRASIL, 2015). Entretanto, a saída de parte dos sujeitos que moravam em áreas centrais em direção à periferia da cidade, seja em função da impossibilidade financeira de manter um imóvel alugado ou da remoção em áreas que foram ocupadas pela expansão do porto são qualificados não como problemas, mas como consequências do processo de desenvolvimento.

Os dados apresentados ao longo do texto evidenciam que mudanças ocorreram no cotidiano da cidade, devido aos trabalhadores de outras regiões, oscilações nos níveis de emprego e desemprego, aumento dos índices de criminalidade, oscilações nos valores dos imóveis, etc. Entretanto, acredita-se, a indústria naval provocou mudanças mais profundas na vida das pessoas, mudanças que não podem ser evidenciadas em indicadores, alterando a forma como o intercâmbio ser humano/natureza é realizado. Os investimentos chegaram e, com a crise econômica, estão partindo. Essa partida deixa marcas na população: trabalhadores desempregados, migrantes sem recursos para voltar para casa, empreendedores endividados, moradores deslocados de suas residências, entre outros.

\section{CONSIDERAÇÕES FINAIS}

REAd | Porto Alegre - Vol. 24 - No 3 - Setembro / Dezembro 2018 - p. 102-129 
As transformações ocorridas em Rio Grande, no período de 2005 a 2017, demonstram como a indústria naval influenciou o ambiente e a vida cotidiana na cidade. Capital (trans)nacional e políticas governamentais foram direcionados de forma articulada, ainda que com distintos interesses, para a criação de novos mecanismos de produção, os quais, por sua vez, organizaram formas de produzir e reproduzir a vida ali existente.

Ainda que, no âmbito das relações de capital, o trabalho exista enquanto trabalho para o capital (MARX, 1996), a categoria organização do trabalho permitiu reconhecer que o trabalho só pode ser pensado enquanto constituído e constituinte dos próprios trabalhadores, mesmo quando superexplorado, como nas terceirizações, nos contratos frágeis ou na precariedade de suas vidas.

A articulação de elementos teóricos dos referenciais de Marx, Lukács e Marini deixa claro as formas pelas quais o capital determina a organização do trabalho com o apoio de políticas públicas nas economias dependentes. No caso de Rio Grande, a defesa do investimento privado nacional e estrangeiro foi associada a uma promessa de melhoria das condições gerais de vida da população que não se cumpriu. Essa articulação entre capital e governo, no entanto, não encerra a organização, que é tensionada por forças antagônicas originadas pelos trabalhadores. Com isso, esse artigo contribui para a teoria no que propõe uma definição de organização do trabalho, termo efetivamente mais mencionado do que desenvolvido em artigos e outros textos que pretendem versar sobre o tema. Estes, no esteio da teoria do processo de trabalho (BRAVERMAN, 1987), acabam tratando a organização do trabalho como o processo produtivo, a divisão do trabalho ou abordando a alienação do trabalhador em relação ao produto de sua atividade, evidenciando uma noção estruturalista do que seria a 'organização'.

A apresentação da categoria que aqui realizamos, por sua vez, não é apenas uma maneira de definir o processo produtivo, ou mesmo um modelo de produção (fordista, toyotista, etc.), ao contrário do que a literatura mais divulgada sobre o tema apresenta (ANTUNES, 2008; 2009; ANTUNES e ALVES; 2004; PINTO, 2003; VASAPOLLO, 2006). Tampouco se resume a um fator para a implementação de inovações tecnológicas no processo produtivo e regulador dos efeitos destas no mercado de trabalho (FERRAZ; CUNHA; FARIA, 2018). Mas, as implicações da organização do trabalho, como proposta neste texto, ultrapassam os muros das indústrias capitalistas e definem formas possíveis às vidas dos trabalhadores e dos habitantes das cidades, posto que o trabalho caracteriza-se como fenômeno originário e modelo da práxis social (LUKÁCS, 2012). 
Ao articular processo produtivo, matriz produtiva, incentivo governamental a determinada atividade, as repercussões do trabalho para a vida do trabalhador e, consequentemente, para determinada localidade, às lutas e resistências dos trabalhadores, a categoria organização do trabalho aqui proposta coloca em evidência as contradições em que os mesmos trabalhadores que têm suas vidas limitadas pelas exigências do capital, resistem aos avanços deste, via ações sindicais até iniciativas mais pontuais no ambiente de trabalho, passando pelas respostas organizadas por outros atores sociais.

Apresentar a articulação entre governos e capitais em torno de uma estratégia dependente de desenvolvimento que acaba por determinar a vida dos trabalhadores e da população em geral é a maior contribuição teórica da categoria organização do trabalho. Ela explicita como a vida é construída e alterada a cada novo ciclo econômico de acordo com o resultado da relação de forças que se estabelece entre capital e trabalho. Ou seja, a partir da determinação de como se dá o trabalho, em sua intensidade, duração, procedimentos e estrutura para a organização da vida para além do trabalho em sentido estrito.

A categoria permitiu um olhar amplo e crítico dos ciclos econômicos no município do Rio Grande, em especial do último: o da indústria naval. Foram colocadas em evidência as intenções governamentais articuladas ao mercado e o constante processo de organização da vida dos trabalhadores no processo de ascensão e ocaso da indústria naval.

Em Rio Grande, onde realizamos a pesquisa, mesmo que as resistências observadas tenham sido insuficientes para romper com o protagonismo da associação entre capital e governo, essas ações demonstraram como a organização do trabalho extrapolou os pátios das fábricas e os muros dos estaleiros e instaurou-se, também, em praça pública, nas casas e dormitórios dos trabalhadores, nas agremiações, nos locais de lazer, enfim, na vida cotidiana da cidade, determinando-a a partir dos mecanismos de produção criados, ou abandonados, de acordo com o momento experimentado pela indústria naval. Isso, sem mencionar as repercussões para além da cidade e do estado, com os trabalhadores migrantes que se deslocaram para a região.

Em termos da dependência em relação às economias centrais, a orientação ao mercado internacional, de matriz agrário-extrativista, não se encerra com o ocaso da indústria naval. Pelo contrário, a reforça. Os governos nacional, estadual e local, crentes na promessa de crescimento econômico, não viram alternativas que não estivessem vinculadas a investimentos externos, reproduzindo, novamente, a relação de dependência econômica exposta neste texto. 
Assim, o capital dependente, que tem na superexploração dos trabalhadores o mecanismo de compensação de suas perdas nas trocas internacionais (MARINI, 1973), culmina em uma forma específica de produção da vida dos trabalhadores. Imersos em uma consciência submetida à reificação que nasce das formas mercantis, na qual o trabalho humano não é mais do que mera abstração, os trabalhadores tendem a imbricar-se paulatinamente na servidão ao capital, enquanto tentam libertar-se dele (LUKÁCS, 2012). Assim, a (re)organização do trabalho em Rio Grande atinge os aspectos mais triviais do cotidiano dos trabalhadores, invadindo pessoalmente suas vidas individuais e comunitária, limitando as possibilidades de transcendência do trabalho.

\section{REFERÊNCIAS}

ANTUNES, Ricado. Afinal, quem é a classe trabalhadora hoje? Revista da Rede de Estudos do Trabalho, ano II, n. 03, 2008.

. Os sentidos do trabalho - ensaios sobre a afirmação e a negação do trabalho. $2^{\mathrm{a}}$ ed. São Paulo: Boitempo, 2009.

ANTUNES, Ricardo; ALVES, Giovanni. As mutações no mundo do trabalho na era da mundialização do capital. Educ. Soc., Campinas, v. 25, n. 87, p. 335-351, mai/ago. 2004. ÁVILA, Karoline. Trabalhadores do Polo Naval protestam por melhores condições de moradia. Jornal Agora. Rio Grande, 27 fev. 2014. Disponível em: $<\mathrm{http}: / / \mathrm{www}$.jornalagora.com.br/site/content/noticias/detalhe.php? $=3 \& \mathrm{n}=55584>$. Acesso em 20 set. 2015 .

BRASIL. Programa de Aceleração do Crescimento 2007-2010: material para imprensa. Brasília, 2007. Disponível em: $<$ http://www.fazenda.gov.br/portugues/releases/2007/r220107-PAC-integra $>$. Acesso em 26 jan. 2016.

BRASIL. PAC 2 - O círculo virtuoso do desenvolvimento, Março-Abril/2012. Disponível

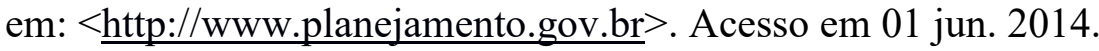

BRASIL. Renda média domiciliar per capita, 2015. Disponível em:

$<$ http://tabnet.datasus.gov.br/cgi/deftohtm.exe?ibge/censo/cnv/rendars.def $>$. Acesso em 16 jun.15.

BRASIL. Ministério do Trabalho e do Emprego. Dados e Estatísticas. Brasília, 2017.

Disponível em: < http://acesso.mte.gov.br/dados_estatisticos>. Acesso em: 10 jan. 2018. 
BRAVERMAN, H. Trabalho e Capital Monopolista: a degradação do trabalho no Século XX. 3 ed. Rio de Janeiro: Ed. Guanabara, 1987.

BRESSER-PEREIRA, L. C. O novo desenvolvimentismo e a ortodoxia convencional. São Paulo em Perspectiva, v. 20, n. 3, p. 5-24, 2006.

CANO, W. Desequilíbrios regionais e concentração industrial no Brasil (1930-1970). São Paulo: Globo, 1985.

CARVALHO, Diogo Sá; CARVALHO, Andrea Bento; DOMIINGUES, Marcelo Vinicius de La Rocha. Polo Naval e Desenvolvimento Regional na Metade Sul do Rio Grande do Sul. In: ENCONTRO DE ECONOMIA GAÚCHA, 6., 2012, Porto Alegre. Anais... Porto Alegre: Pontíficia Universidade Católica do Rio Grande do Sul, 2012. Disponível em: $<$ http://www.pucrs.br/eventos/eeg/download/Mesa7/Polo_Naval_e_Desenvlvimento_Regiona 1_da_Metade_Sul_do_RS.pdf $>$. Acesso em: 11 out. 2015.

CONFEDERAÇÃO NACIONAL DO COMÉRCIO DE BENS, SERVIÇOS E TURISMO.

Empresômetro MPE. Brasília, 2015. Disponível em:

$<$ http://empresometro.cnc.org.br/Estatisticas>. Acesso em: 15 set. 2015.

COPSTEIN, R. O trabalho estrangeiro no município do Rio Grande. Porto Alegre, Boletim Gaúcho de Geografia, n.4, 1975, p.1-43.

COSTA, A. O Rio Grande do Sul. Porto Alegre: Globo, 1922.

DEPARTAMENTO DE INFORMÁTICA DO SISTEMA ÚNICO DE SAÚDE. Informações de Saúde (TABNET). Brasília, 2017. Disponível em:

$<\mathrm{http}$ //www2.datasus.gov.br/DATASUS/index.php?area=02>. Acesso em: 10 ago. 2017.

DORNELAS CAMARA, Guilherme. Os Programas Sociais de Combate à Pobreza na Argentina e no Brasil: uma abordagem da Filosofia da Libertação. 2014. 223 f. Tese (Doutorado em Administração) - Programa de Pós-Graduação em Administração, Escola de Administração, Universidade Federal do Rio Grande do Sul. Porto Alegre, 2014. Disponível em: < http://hdl.handle.net/10183/96901>. Acesso em: 10 out. 2015.

FERRAZ, Deise L.; CUNHA, Elcemir P.; FARIA, José H. GT 2 - Acumulação de Capital: organização do trabalho, tecnologia e finanças. SBEO. Sociedade Brasileira de Estudos Organizacionais. $2^{\text {a }}$ Convocatória para o V Congresso Brasileiro de Estudos Organizacionais. Curitiba, 2018. Disponível em: $<$ http://www.sbeo.org.br/web/index.php/cbeo/v-cbeo $>$. Acesso em 08 jul. 2018. FUNDAÇÃO DE ECONOMIA E ESTATÍSTICA SIEGFRIED EMANUEL HEUSER. Dados Municipais. Porto Alegre, 2017. Disponível em: $<$ http://www.fee.tche.br $>$. Acesso em: 18 ago. 2017.

REAd | Porto Alegre - Vol. 24 - No 3 - Setembro / Dezembro 2018 - p. 102-129 
FUNDAÇÃO INSTITUTO BRASILEIRO DE GEOGRAFIA E ESTATÍSTICA. Cidades.

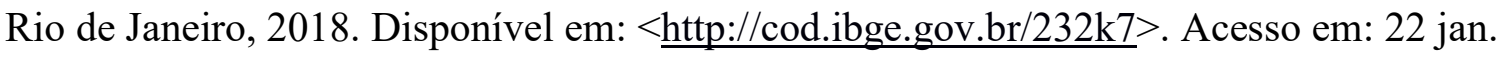
2018 .

JORNAL AGORA. Incêndio atinge alojamento de trabalhadores no centro da cidade. Jornal Agora. Rio Grande, 25 mar. 2013. Disponível em: $<$ http://www.jornalagora

.com.br/site/content/noticias/detalhe.php?e=7\&n=41342>. Acesso em: 20 set. 2017.

JORNAL AGORA. Quip chega aos seis anos em Rio Grande com novo investimento privado. Disponível em: <www.jornalagora.com.br>. Acesso em 16 jun.15.

LUKÁCS, György. História e consciência de classe: estudos sobre a dialética marxista. $2^{\mathrm{a}}$ ed. São Paulo: Martins Fontes, 2012.

MARINI, Ruy Mauro. A acumulação capitalista mundial e o subimperialismo. Revista Outubro, n. 20, p. 27-70, 2012. Disponível em:

$<$ http://www.revistaoutubro.com.br/edicoes/20/out20_02.pdf >. Acesso em: 10 ago. 2015. MARINI, Ruy Mauro. Dialética da dependência: 1973. In: TRASPADINI, Roberta; STEDILE, João Pedro (Orgs.). Rui Mauro Marini: vida e obra. São Paulo: Expressão Popular, 2005. p. 137-180.

MARTINS, Solismar Fraga; PIMENTA, Margareth de Castro Afeche. A constituição espacial de uma cidade portuária através dos ciclos produtivos industriais - $\mathrm{O}$ caso do município de Rio Grande (1874-1970). Revista Brasileira de Estudos Urbanos e Regionais, Recife, v.6, n.1, p. 85-100, 2004. Disponível em: $<$ http://repositorio.furg.br:8080/handle/1/810>. Acesso em: 10 out. 2014.

MARX, Karl. O Capital: crítica da economia política. Livro I. Volume II. São Paulo: Nova Cultural, 1996.

Trabalho Assalariado e Capital \& Salário, Preço e Lucro. $1^{\text {a }}$ ed. São Paulo: Expressão Popular, 2006.

. Crítica ao Programa de Gotha. In: ANTUNES, Ricardo (org.). A dialética do trabalho. Volume I. São Paulo: Expressão Popular, 2013.

O Capital: crítica da economia política. Livro I. Volume I. $33^{\mathrm{a}}$ ed. Rio de Janeiro: Civilização Brasileira, 2014.

MERCADANTE, A. Brasil: a construção retomada. São Paulo: Terceiro Nome, 2010. PESAVENTO, S. J. História do Rio Grande do Sul. Porto Alegre: Mercado Aberto, 1990. PINTO, Geraldo Augusto. Reestruturação produtiva e organização do trabalho na indústria de autopeças no Brasil. 2003. 353f. Dissertação (Mestrado em Sociologia). Departamento de Sociologia, Instituto de Filosofia e Ciências Humanas, Universidade 
Estadual de Campinas, Campinas, 2003. Disponível em: $<$ http://www.

bibliotecadigital.unicamp.br/document/?code=vtls000308432>. Acesso em: 05 jan. 2016.

PINTO, Rafhael Colvara. A Cidade como Espaço de Acolhida: o Pensar Teológico no contexto do Polo Naval na cidade do Rio Grande/RS. 2014. 94 f. Dissertação (Mestrado em Teologia) - Programa de Pós-Graduação em Teologia, Pontifícia Universidade Católica do

Rio Grande do Sul, Porto Alegre, 2014. Disponível em: <http://hdl.handle.net/10923/5782>. Acesso em: 20 out. 2015.

POLL, Anete. Incêndio atinge mais um alojamento de trabalhadores. Jornal Agora. Rio Grande, 14 jun. 2013. 2013a. Disponível em:

$<$ http://www.jornalagora.com.br/site/content/noticias/detalhe.php?e=7\&n=44693 $>$. Acesso em 20 set. 2015 .

POLL, Anete. Condições de alojamentos desagradam trabalhadores. Jornal Agora. Rio Grande, 30 jun. 2013. 2013b. Disponível em: < http://www.jornalagora.com.br/site/content/noticias/detalhe.php?e=3\&n=45357>. Acesso em 20 set. 2015 .

PORTAL DO EMPREENDEDOR. Relatórios Estatísticos do MEI. Brasília, 2017.

Disponível em: $<$ http://www.portaldoempreendedor.gov.br/estatistica/relatorios-estatisticosdo-mei>. Acesso em 15 jan. 2018.

RANDS, M. A era Lula - desenvolvimento, democracia e cultura política no Brasil. Recife: Bagaço, 2010.

RIO GRANDE DO SUL. Porto do Rio Grande bate recorde no $1^{\circ}$ semestre de 2014. Disponível em: <http://www.portoriogrande.com.br/site/noticias_detalhes.php?idNoticia $=1559>$. Acesso em 16 jun. 15 .

RIO GRANDE DO SUL. Porto do Rio Grande. Disponível em: <www.portoriogrande.com.br>. Acesso em: 27 fev. 2018.

ROUSSEFF, D. Discurso da Presidenta da República, Dilma Rousseff, durante Compromisso Constitucional perante o Congresso Nacional. Disponível em: $<$ http://www2.planalto.gov.br>. Acesso em 01 ago. 2011.

SALVATORI, E. et al. Crescimento horizontal da cidade do Rio Grande. Revista do IBGE, 1989.

SILVA, R. P. et al. O impacto do Polo Naval no setor imobiliário da Cidade do Rio Grande/RS. In: $6^{\mathbf{0}}$ encontro de economia gaúcha, 2012, Porto Alegre. PUC/RS, 2012. Disponível em: 
$<$ http://cdn.fee.tche.br/eeg/6/mesa3/O_Impacto_do_Polo_Naval_no_Setor_Imobiliario_da_ci dade_de_RioGrande_RS.pdf>.Acesso em: 07 jul. 2017.

SINAVAL. Informações do setor. Sindicato Nacional da Indústria Construção e Reparação Naval Offshore, 2009. Disponível em: <http://www.sinaval.org.br>. Acesso em 20 jun. 2013. SINDICATO DA INDÚSTRIA DA CONSTRUÇÃO E REPARAÇÃO NAVAL E OFFSHORE. Empregos. Rio de Janeiro, 2015. Disponível em:

$<$ http://www.sinaval.org.br/empregos >. Acesso em: 20 ago. 2015.

VASAPOLLO, Luciano. O trabalho atípico e a precariedade - elemento estratégico determinante do capital no paradigma pós-fordista. In.: ANTUNES, Ricardo (org.). Riqueza e Miséria do Trabalho no Brasil. São Paulo: Boitempo, 2006. 